\title{
Global climate interdisciplinary science for the COP17 in Durban, South Africa
}

\author{
Luc Hens • David Pimentel
}

Received: 21 February 2011/Accepted: 28 July 2011/Published online: 9 October 2011

(C) Springer Science+Business Media B.V. 2011

The year 2010 is one of the warmest since we started keeping track of climate data in the early 1800s. Temperature records have been measured in 17 countries, including Pakistan where on May 26 th, $53.5^{\circ} \mathrm{C}$ was noticed. In Russia, last summer, temperatures of $40^{\circ} \mathrm{C}$ were reached, and the resulting drought caused vast forest fires for weeks. These fires were responsible for hundreds of human deaths and covered Moscow and its environs with toxic smog for weeks. Extreme reductions of soil moisture made the wheat yields in Russia, Ukraine and Kazakhstan fall by over $40 \%$.

Never before, have so many inundations and extreme weather events been put on the records in 1 year. Pakistan faced not only high temperatures but also devastating floods that made more than four million people homeless and in vast areas reduced the crop harvest to zero. Similar events were reported in Central Vietnam and other countries in Southeast Asia.

Increases in air and surface water temperatures and sea level rises threaten the very existence of small island states, while arctic sea ice, glaciers and spring snow in the Northern hemisphere decrease.

Polar ice sheets break off, and Greenland is losing its ice cover at a rate of 100 cubic kilometers a year. At the same time, Europe is experiencing its hardest winter since the 1940s.

Even, when none of these individual events can be attributed to climate changes induced by humans, altogether they provide a picture of extreme weather events as predicted more than 20 years ago by the Intergovernmental Panel on Climate Change (IPCC).

To counteract these problems, the international community concluded action was needed already in 1992 at the occasion of the UNCED conference in Rio de Janeiro, the UN Framework Convention on Climate Change. On December 10th 2010, the 16th session of the conference of parties (COP16) to this convention was concluded in Cancún (Mexico). The results were discouraging from a scientific point of view. Even more than in

Readers should send their comments on this paper to BhaskarNath@aol.com within 3 months of publication of this issue.

L. Hens $(\bowtie) \cdot$ D. Pimentel

Free University Brussels, Brussels, Belgium

e-mail: luchens51@gmail.com 
Copenhagen (Denmark), last year, it became obvious that the developed countries do not want to bring down their greenhouse gas emissions to an environmentally acceptable level, which would result in only a $2^{\circ} \mathrm{C}$ rise, relative to pre-industrial temperatures, or preferentially less, of the overall temperature worldwide. Moreover, this situation opens opportunities for industrialized countries to favor more risky options such as geo-engineering and carbon trading that have uncertain outcomes.

This is particularly serious because it becomes increasingly clear that the most dramatic consequences of climate changes are felt in developing countries. This applies to the direct effects that are listed at the beginning of this editorial, but even more to the indirect effects. Currently, more than $60 \%$ of the world population is malnourished, the largest number in history. Oil is projected to be seriously depleted by late 2050, oil is critical to food production.

If the world wants to make progress on climate change policy, new, complementary strategies to the existing ones will be necessary. These strategies should not only be adequate and effective, but also more equitable, by putting the burden on those who caused most of the problem. It is currently unclear what these new strategies will entail, but they will necessitate a sound interdisciplinary approach. It is equally obvious that we deal here with a core problem of environment, development and sustainability. Therefore, this journal will most welcome scientific, data-based contributions that are next logical steps forward in the direction of the COP17 in Durban (South Africa). 